\title{
Vigor e viabilidade de sementes de trigo tratadas com zinco
}

\author{
Silvana Ohse * \\ Jonathan Gomes Cubis \\ Bráulio Luciano Alves Rezende \\ Marluce Gonçalves Cortez \\ Rosana Fernandez Otto \\ Centro de Ciências Agrárias e Tecnologia \\ Universidade Estadual de Ponta Grossa \\ CEP 34030-900, Ponta Grossa - PR, Brasil \\ * Autor para correspondência \\ sohse@uepg.br
}

Submetido em 06/11/2011

Aceito para publicação em 18/07/2012

\section{Resumo}

O zinco tem sido utilizado na formulação de produtos denominados fitoestimulantes, atuando no alongamento celular e formação de raízes laterais. Dessa forma, este trabalho teve como objetivo avaliar o efeito de doses de zinco aplicadas em tratamento de sementes sobre a germinação e o vigor de cultivares de trigo. O experimento constou de duas cultivares de trigo (Quartzo e Supera) e sete doses de zinco aplicadas em tratamento de sementes na forma $\mathrm{ZnSO}_{4} \cdot 7 \mathrm{H}_{2} \mathrm{O}(0 ; 0,19 ; 0,38 ; 0,76 ; 0,95 ; 1,14 ;$ e $1,52 \mathrm{~g}$ de Zn.kg-1 de sementes $)$, constituindo um fatorial $2 \times 7$ em delineamento inteiramente casualizado, com quatro repetições. As doses de zinco não influenciaram a germinação de sementes de trigo, denotando a não existência de toxicidade e a possibilidade de se fornecer zinco via semente para a cultura. No entanto, a cultivar Quartzo apresentou germinação superior a Supera. Quanto ao vigor, as cultivares responderam de forma diferenciada às doses de zinco aplicadas via sementes. A cultivar Quartzo teve o comprimento de plântula aumentado até a dose de $0,56 \mathrm{~g} . \mathrm{Zn} \cdot \mathrm{kg}^{-1} \mathrm{de}$ sementes. Doses de zinco entre 0,76 e $1,04 \mathrm{~g} . \mathrm{kg}^{-1}$ de sementes proporcionaram maior vigor às sementes de trigo cultivar Supera. Conclui-se que a germinação de sementes das cultivares Quartzo e Supera não foi afetada pela aplicação de zinco em tratamento de sementes, no entanto, em relação ao vigor a cultivar Supera foi mais responsiva, por ter apresentado aumentos significativos na maioria das variáveis avaliadas.

Palavras-chave: Sulfato de zinco; Tratamento de sementes; Triticum aestivum L.

\section{Abstract}

Vigor and viability of wheat seeds treated with zinc. Zinc has been used in the formulation of products named phytostimulants, acting on cell elongation and lateral root formation. Thus, this paper aimed to evaluate the effect of doses of zinc applied in seed treatment on germination and vigor of wheat cultivars. The experiment consisted of 2 cultivars of wheat (Quartzo and Supera) and 7 doses of zinc applied in seed treatment in the form

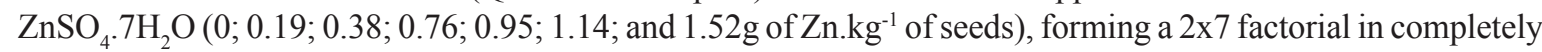
randomized design with 4 replications. The doses of zinc did not influence on the germination of wheat seeds, 
denoting the absence of toxicity and the possibility of providing zinc via seed for culture. However, the cultivar Quartzo presented a higher germination than Supera. Regarding vigor, the cultivars responded differently to doses of zinc applied through seeds. The cultivar Quartzo had an increased seedlings length up to a dose of 0,56g. $\mathrm{Zn} . \mathrm{kg}^{-1}$ of seeds. Doses of zinc between 0.76 and $1.04 \mathrm{~g} \cdot \mathrm{kg}^{-1}$ of seeds provided a higher vigor to wheat seeds of the cultivar Supera. One concludes that the germination of seeds of the Quartzo and Supera cultivars was not affected by application of zinc in seed treatment, however, with regard to vigor, the Supera cultivar was more responsive, as it presented significant increases in most of the variables evaluated.

Key words: Treatment of seeds; Triticum aestivum L.; Zinc sulfate

\section{Introdução}

Componente básico na alimentação dos mais variados povos, cultivado desde 5.000 a.C., o trigo (Triticum aestivum L.), é responsável por grande parte da dieta da população mundial. Além disso, o cereal é matéria-prima utilizada em larga escala na elaboração de vários produtos alimentícios, colas, bebidas e pequena parcela é destinada à alimentação animal (BRUNETTA et al., 2004).

Altamente dependente da importação desse grão, o Brasil, na safra 2010, produziu cerca de 5,9 milhões de toneladas de trigo, atendendo apenas parte da demanda de seu mercado interno, a qual é de aproximadamente 10 milhões de toneladas ao ano. Atualmente, o Estado do Paraná é o maior produtor do grão no país, sendo responsável por mais de 56\% da produção na última safra (CONAB, 2011). Estudos revelam que o país tem condições de ser autossuficiente na produção de trigo, porém, fatores como dificuldades de comercialização, melhor qualidade do produto estrangeiro, baixa tecnologia e falta de informações por parte dos produtores brasileiros têm se apresentado como obstáculos para o alcance de maiores rendimentos (EMBRAPA TRIGO, 2007). Com isso, há necessidade de alavancar a produção tritícola nacional, visando aumentar a produção e melhorar a qualidade do grão, valorizando-o e aumentando sua competitividade no mercado.

A cultura é umas das principais alternativas de cultivo durante a época de inverno, principalmente na região sul do Brasil. Contribui no controle da erosão e favorece o sistema plantio direto pelo volume de palha que permanece sobre a superfície do solo após a colheita. Estima-se em $20 \%$ a redução dos custos nas lavouras de verão precedidas pelo trigo. A cultura também se mostra como importante fonte de oportunidade de trabalho e geração de renda no meio rural (COLLE, 1998).

A expansão das áreas agrícolas, o aumento da qualidade dos fertilizantes produzidos e o aumento do rendimento das diversas culturas nas safras, resultante de técnicas mais avançadas advindas da pesquisa podem, ao longo dos anos, acarretar o aparecimento de deficiências de micronutrientes no solo e, consequentemente comprometer os índices de produção. A manutenção dos teores de micronutrientes disponíveis para as plantas merece atenção especial no sentido de se garantir e melhorar os bons resultados alcançados nos últimos anos (LEANDRO et al., 2002).

$\mathrm{Na}$ agricultura brasileira, o zinco $(\mathrm{Zn})$ é provavelmente o micronutriente cuja deficiência é mais comum, tanto em culturas anuais como em culturas perenes (MALAVOLTA, 2006). Quando o Zn encontra-se em quantidades insuficientes no solo, não suprindo a exigência vegetal, anormalidades podem ser encontradas e, consequentemente o rendimento das culturas será comprometido. A transferência do $\mathrm{Zn}$ do solo para as raízes ocorre, em sua maioria, por difusão, caracterizando a baixa mobilidade do elemento no solo, dificultando sua absorção pela planta (MALTA, 2000).

$\mathrm{O}$ fornecimento de micronutrientes, como o $\mathrm{Zn}$, às culturas pode ser feito diretamente no solo (na forma de adubos), na planta (através de adubação foliar) ou pelo tratamento de sementes (MALAVOLTA, 2006). Devido ao fato do $\mathrm{Zn}$ ser requerido em pequenas quantidades pelas plantas, dá-se ênfase à sua adição via tratamento de sementes, por apresentar vantagens relacionadas à uniformidade de distribuição sobre as sementes e redução de gastos pela minimização da quantidade aplicada quando comparada com a adubação via solo e 
foliar, resultando na racionalização do uso de matérias primas não renováveis (PARDUCCI et al., 1989). O tratamento de sementes com micronutrientes tem como objetivo sua translocação para a futura planta. Assim, os teores iniciais de micronutrientes das sementes podem ser aumentados, ajudando no desenvolvimento, tornando-se importante fonte para a nutrição da planta oriunda dessas sementes enriquecidas (PESSOA et al., 1996).

O agricultor, para ser competitivo no mercado, necessita aumentar o rendimento das culturas e, ao mesmo tempo, reduzir seus custos. Para isso, algumas práticas se fazem necessárias e o uso de micronutrientes tem se apresentado como importante alternativa. O uso de micronutrientes na agricultura brasileira intensificouse nos últimos anos, tendo contribuído para isso, fatores como o desenvolvimento de novas cultivares com elevado potencial produtivo, implicando em maior acúmulo de nutrientes nos grãos e com isso maior exportação, diminuindo progressivamente sua disponibilidade nos solos. Além disso, o avanço das fronteiras agrícolas para solos ácidos e pobres, com consequente correção de sua acidez, eleva o pH da solução do solo, diminuindo acentuadamente a disponibilidade da maioria dos micronutrientes (FAVARIN; MARINI, 2000).

Altos rendimentos só podem ser obtidos com plantas bem nutridas e a deficiência de qualquer nutriente pode limitá-la, ou até mesmo prejudicar a qualidade do produto final. Neste aspecto, o $\mathrm{Zn}$, embora requerido em pequena quantidade, desempenha importantes funções na planta. A participação do Zn na planta é essencial para a síntese do aminoácido triptofano, precursor do ácido indolacético (AIA), principal auxina produzida pelas plantas. A auxina, por sua vez, é um fitormônio, responsável pelo alongamento e divisão celular, formação de raízes adventícias e laterais, tropismos, dominância apical, e outras funções (TAIZ; ZEIGER, 2009).

Muitas enzimas possuem o $\mathrm{Zn}$ como constituinte ou ativador, entre elas estão a anidrase carbônica, desidrogenases, aldolases, enolases, isomerases, RNAase, RNA polimerase, nitrato redutase, álcool desidrogenase, entre outras (MARENCO; LOPES, 2007). Dentre os processos que são influenciados pelo $\mathrm{Zn}$ tem-se a fotossíntese, processo em que há participação da anidrase carbônica (localizada no citoplasma e cloroplastos), uma importante enzima catalisadora da formação do ácido carbônico, o qual participa da neutralização do $\mathrm{pH}$ celular. Outro processo influenciado é a atividade respiratória, a qual é reduzida em caso de deficiência de $\mathrm{Zn}$, pois a aldolase, enzima chave na glicólise, depende da sua presença para funcionar, consequentemente há redução da síntese de ATP (TAIZ; ZEIGER, 2009).

O Zn inibe a RNAase (desintegradora de RNA), além disso, o elemento faz parte da RNA polimerase, que sintetiza RNA e, por isso, em condições de deficiência, há diminuição da síntese de proteínas devido à falta dos RNAs mensageiro e transportador. O processo de redução de nitrato (principal forma de Nitrogênio absorvida pelas plantas) a nitrito depende da enzima nitrato redutase. Quando há deficiência de Zn, ocorre acúmulo de nitrato, fato que pode ser explicado devido à menor indução na síntese da enzima (MALAVOLTA, 2006).

Em razão das pequenas quantidades exigidas pelas culturas, as deficiências de micronutrientes são as últimas que aparecem em solos cultivados. A remoção pelas culturas reduz os teores no solo, que, aliado ao crescente aumento do rendimento das mesmas, acelera grandemente essas remoções. No caso específico do Zn, este tem sua disponibilidade afetada pelo $\mathrm{pH}$, quando acima de 6,0, devido ao aumento dos teores de cálcio e magnésio através da calagem, fato que pode ocasionar sua deficiência nas plantas (RAIJ, 1991). Além disso, o elemento é fortemente retido em solos argilosos e a prática de adubações fosfatadas tende a aumentar o requerimento fisiológico de $\mathrm{Zn}$ por parte da planta, o que pode agravar sua deficiência (WEBB; LONERAGAN, 1988).

Sabendo-se da importância do Zn para o desenvolvimento das plantas, principalmente em solos naturalmente pobres no micronutriente como os dos Campos Gerais - PR, os quais são derivados de arenito, este trabalho teve como objetivo avaliar o efeito de doses de $\mathrm{Zn}$ aplicadas via tratamento de sementes sobre a germinação e o vigor de sementes de cultivares de trigo, devido à carência de estudos nesse sentido, uma vez que 
a cultura constitui-se em excelente alternativa de cultivo de inverno para a região.

\section{Material e Métodos}

O experimento foi desenvolvido no Laboratório de Análise de Sementes do Departamento de Fitotecnia e Fitossanidade da Universidade Estadual de Ponta Grossa - Ponta Grossa, Paraná, durante o período de 26 de maio a 20 de dezembro de 2010. Para a realização do experimento utilizaram-se duas cultivares de trigo da OR Melhoramento de Sementes Ltda/Biotrigo Genética Ltda. As sementes não haviam sido submetidas a nenhum tipo tratamento antes da implantação do experimento.

Os tratamentos constaram da combinação de dois cultivares de trigo (Quartzo e Supera) e de sete doses de Zn $(0 ; 0,19 ; 0,38 ; 0,76 ; 0,95 ; 1,14$ e 1,52g

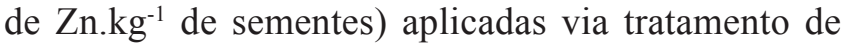
sementes, constituindo um experimento fatorial $2 \times 7$ (14 tratamentos), desenvolvido em delineamento inteiramente casualizado, com quatro repetições. A definição das doses estudadas foi baseada no trabalho desenvolvido por Ohse et al. (1999) com a cultura do arroz irrigado, no qual obtiveram como dose de máxima eficiência técnica $0,76 \mathrm{~g}$ de $\mathrm{Zn} \cdot \mathrm{kg}^{-1}$ de sementes.

Como fonte de $\mathrm{Zn}$ utilizou-se o sulfato de zinco $\left(\mathrm{ZnSO}_{4} \cdot 7 \mathrm{H}_{2} \mathrm{O}\right)$, apresentando massa molecular de 287,54 e $22,74 \%$ de $\mathrm{Zn}$. As quantidades de $\mathrm{ZnSO}_{4} .7 \mathrm{H}_{2} \mathrm{O}$ correspondentes às doses selecionadas foram dissolvidas em $5 \mathrm{~mL}$ de água destilada e distribuídas sobre uma porção de $50 \mathrm{~g}$ de sementes acondicionadas em sacos plásticos. Posteriormente, os sacos plásticos foram fechados e agitados até a completa uniformização do produto sobre as sementes, sendo em seguida, deixados abertos para secagem das sementes tratadas à sombra. A testemunha passou pelo mesmo processo, porém foi umedecida somente com $5 \mathrm{~mL}$ de água destilada.

O teste padrão de germinação foi instalado obedecendo às Regras de Análise de Sementes (RAS) para temperatura e avaliação de plântulas (BRASIL, 2009). O teste foi realizado em substrato rolo papel toalha, com quatro repetições de 50 sementes por tratamento, à temperatura de $25^{\circ} \mathrm{C}$. A avaliação foi realizada contando-se as plântulas normais e plântulas anormais + sementes mortas, sendo os dados convertidos em percentagem.

O teste de vigor que avalia o crescimento das plântulas (comprimento e fitomassa seca), foi instalado em substrato de papel toalha, de acordo com a metodologia descrita por Krzyzanowski et al. (1991). Para cada tratamento, utilizaram-se quatro repetições de 20 sementes, as quais foram alinhadas $2 \mathrm{~cm}$ abaixo da borda superior do papel toalha. As repetições foram agrupadas com atilhos de borracha, sendo envolvidas em plástico preto, a fim de manter constante a umidade dos rolos e evitar o efeito da luz sobre as primeiras plântulas emergidas. Em seguida, foram colocadas no germinador, regulado para temperatura constante de $25^{\circ} \mathrm{C}$.

Quando da avaliação do teste de vigor, considerouse apenas as plântulas normais, das quais se mensurou o comprimento da parte aérea, da raiz primária e da plântula inteira. Em seguida, essas partes, sem os restos das sementes, foram pesadas, determinando-se sua fitomassa fresca, sendo posteriormente acondicionadas em sacos de papel e, então colocadas na estufa à temperatura de $65^{\circ} \mathrm{C}$, até atingir fitomassa seca constante.

Os dados obtidos foram analisados estatisticamente através da aplicação da análise da variância pelo teste de $\mathrm{F} \mathrm{e}$, quando de significância para doses ou interação, submetidas à regressão polinomial, utilizando o programa ESTAT. Os dados de percentagem foram transformados em arcoseno $y^{2}=(x+0,5)$ e os gráficos gerados no programa Microsoft Excel.

\section{Resultados e Discussão}

A análise da variância revelou significância para as variáveis de germinação (plântulas normais) e para plântulas anormais + sementes mortas $(\mathrm{PA}+\mathrm{SM})$, tanto para o fator doses de $\mathrm{Zn}$ aplicado via tratamento de sementes quanto para o fator cultivares de trigo $(\mathrm{p}<0,05)$, não apresentando, porém, para a interação entre os fatores. Todavia, quando da análise de regressão polinomial para o fator doses de Zn não houve ajuste a nenhuma equação para ambas as variáveis, contudo para a variável germinação a média foi de $85,34 \%$ com 
coeficiente de variação (CV) de 5,86\%, enquanto para $\mathrm{PA}+\mathrm{SM}$ a média foi de $14,73 \%$ e o CV de $33,79 \%$.

A cultivar Quartzo apresentou germinação 4,47\% superior a Supera e, consequentemente, menor percentagem de $\mathrm{PA}+\mathrm{SM}$, o que provavelmente se deva a variações genotípicas entre as cultivares. Entretanto, observa-se que, independentemente das doses de $\mathrm{Zn}$ aplicadas na forma de $\mathrm{ZnSO}_{4} \cdot 7 \mathrm{H}_{2} \mathrm{O}$ via sementes em ambas cultivares de trigo, a germinação manteve-se acima do valor mínimo de $80 \%$ requerido pelas Normas de Produção de Semente Fiscalizada (NPSF) (BRASIL, 1993), podendo com isso, suprir deficiências nas fases iniciais ou, até mesmo, melhorar o desenvolvimento da cultura (Tabela 1).

TABELA 1: Germinação e plântulas anormais + sementes mortas $(\mathrm{PA}+\mathrm{SM})$ de duas cultivares de trigo, independentemente da dose de $\mathrm{Zn}$ aplicada via tratamento de sementes. UEPG, Ponta Grossa, PR, 2011.

\begin{tabular}{|c|c|c|}
\hline \multirow{2}{*}{$\begin{array}{c}\text { Cultivares de } \\
\text { trigo }\end{array}$} & Germinação & $\mathbf{P A}+\mathbf{S M}$ \\
\hline & \multicolumn{2}{|c|}{ (\%) } \\
\hline Quartzo & $87,3 \mathrm{a}^{*}$ & $12,7 \mathrm{~b}$ \\
\hline Supera & $83,4 \mathrm{~b}$ & $16,6 \mathrm{a}$ \\
\hline Média & 85,36 & 14,64 \\
\hline CV (\%) & 8,62 & 50,26 \\
\hline
\end{tabular}

"Médias seguidas da mesma letra na coluna não diferem entre si pelo teste de Tukey a 5\%.

Funguetto et al. (2010) e Ohse et al. (2001) ao aplicarem doses de Zn em sementes de arroz irrigado, também verificaram que não houve influência significativa sobre a germinação, mantendo-a, porém, acima do valor mínimo exigido pelas NPSF. Contrariamente, Slaton et al. (2001) obtiveram na cultura do arroz, quando da

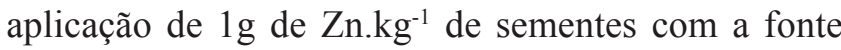
$\mathrm{ZnSO}_{4} \cdot 7 \mathrm{H}_{2} \mathrm{O}$, aumento de $50 \%$ na germinação.

A análise estatística revelou significância para a interação entre os fatores cultivares de trigo e doses de $\mathrm{Zn}$ aplicadas via tratamento de sementes para as variáveis comprimento da parte aérea (CPA), comprimento da raiz (CR) e comprimento da plântula inteira (CPI) $(\mathrm{p}<0,01)$. Quando da análise de regressão, a cultivar Quartzo não apresentou significância para a variável CPA, cuja média foi de $13,38 \mathrm{~cm}$ e o CV de 4,96\%. No entanto, o CPA de plântulas da cultivar Quartzo foi em média 2,5 $\mathrm{cm}$ maior à média da cultivar Supera.
Os dados de CPA de plântula da cultivar Supera ajustaram-se a uma equação de segundo grau em função das doses de $\mathrm{Zn}$ aplicadas via tratamento de sementes, apresentando aumento no CPA até a dose de 1,04g de Zn. $\mathrm{kg}^{-1}$ de sementes, correspondendo a $11,71 \mathrm{~cm}$, o qual é 26,5\% superior à testemunha (Figura 1). Similarmente, Funguetto et al. (2010) obtiveram valor de CPA de plântulas de arroz, quando da aplicação de $\mathrm{Zn}$ via sementes 58\% superior à testemunha com a dose $0,57 \mathrm{~g}$

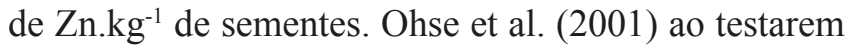
doses de $\mathrm{Zn}$ via tratamento de sementes em arroz irrigado, também verificaram que o CPA foi influenciado significativamente, apresentando valor superior em 9,3\% quando comparado à testemunha.

Para a variável CR, quando da análise de regressão, as cultivares Quartzo e Supera ajustaram-se à equação de segundo grau, apresentando inicialmente acréscimo nos valores de $\mathrm{CR}$ até um ponto de máxima eficiência, decrescendo a partir de então, o que é decorrente, provavelmente, devido à toxicidade causada pelo excesso de $\mathrm{Zn}$. Os pontos de máxima eficiência técnica foram obtidos com as doses 0,56 e $0,76 \mathrm{~g}$ de ${\mathrm{Zn} . \mathrm{kg}^{-1}}^{-}$ de sementes, correspondendo a 12,91 e $15,42 \mathrm{~cm}$, aumentando em 15,0 e 36,1\% quando da comparação à testemunha, respectivamente para as cultivares Quartzo e Supera (Figura 2). Ohse et al. (2001) e Funguetto et al. (2010) encontraram resultados muito próximos para esta variável, ao estudarem doses de $\mathrm{Zn}$ via tratamento de sementes em arroz, com a dose $0,67 \mathrm{~g}^{\mathrm{de}} \mathrm{Zn} \mathrm{kg}^{-1} \mathrm{de}$ sementes. $\mathrm{O}$ aumento no comprimento de raiz devido à aplicação de $\mathrm{Zn}$, provavelmente se deva ao fato deste elemento ser necessário para a síntese do aminoácido triptofano, precursor do fitormônio auxina, responsável principalmente pela diferenciação e alongamento das células da raiz.

Para CPI os dados se ajustaram a equações de segundo grau, apresentando aumentos até as doses de 0,50 e $0,78 \mathrm{~g}$ de $\mathrm{Zn}_{\mathrm{kg}}{ }^{-1}$ de sementes, respectivamente, para as cultivares Quartzo e Supera (Figura 3). A cultivar Supera foi mais responsiva à aplicação de $\mathrm{Zn}$ via tratamento de sementes para esta variável, apresentando aumento de $32,4 \%$ enquanto para a Quartzo o aumentou foi de $4,7 \%$ em relação à testemunha, demonstrando que, características genéticas podem influenciar na resposta. 
Ohse et al. (2001) obtiveram acréscimo de 6,6\% no CPI quando da aplicação de doses de $\mathrm{Zn}$ via tratamento de sementes de arroz irrigado. O aumento do CPI é fator importante, atuando no desenvolvimento inicial das plântulas, podendo auxiliar no estabelecimento da cultura a campo, acelerando sua emergência e, com isso, reduzindo o período de exposição a fatores adversos à germinação e à emergência.

FIGURA 1: Comprimento da parte aérea de plântulas de trigo (CPA), cultivares quartzo e Supera, em função de doses de $\mathrm{Zn}$ aplicadas via tratamento de sementes. UEPG, Ponta Grossa, PR, 2011.

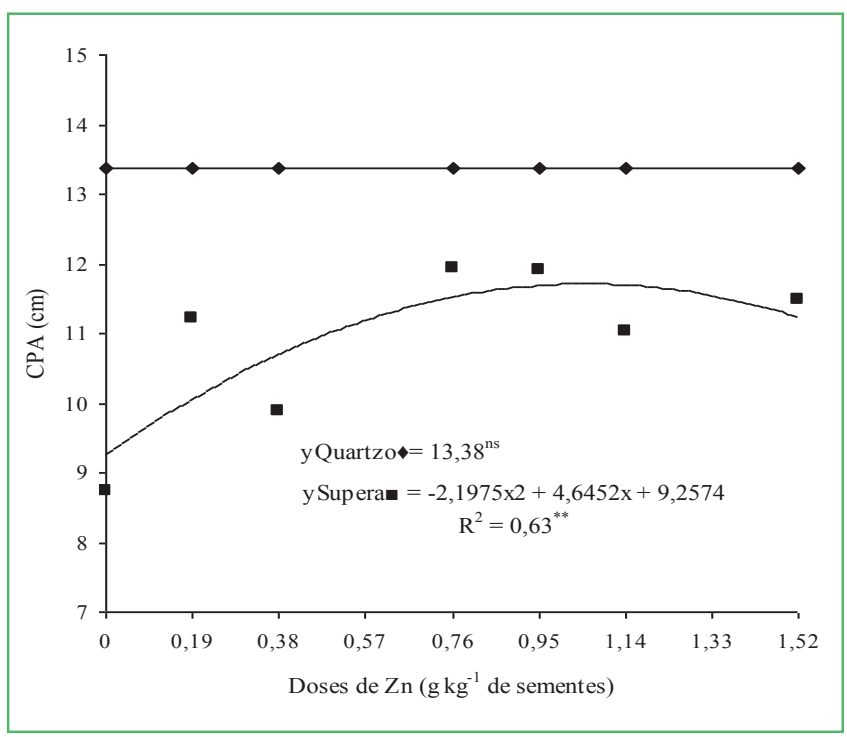

FIGURA 2: Comprimento de raiz de plântulas de trigo (CR), cultivares Quartzo e Supera, em função de doses de $\mathrm{Zn}$ aplicadas via tratamento de sementes. UEPG, Ponta Grossa, PR, 2011.

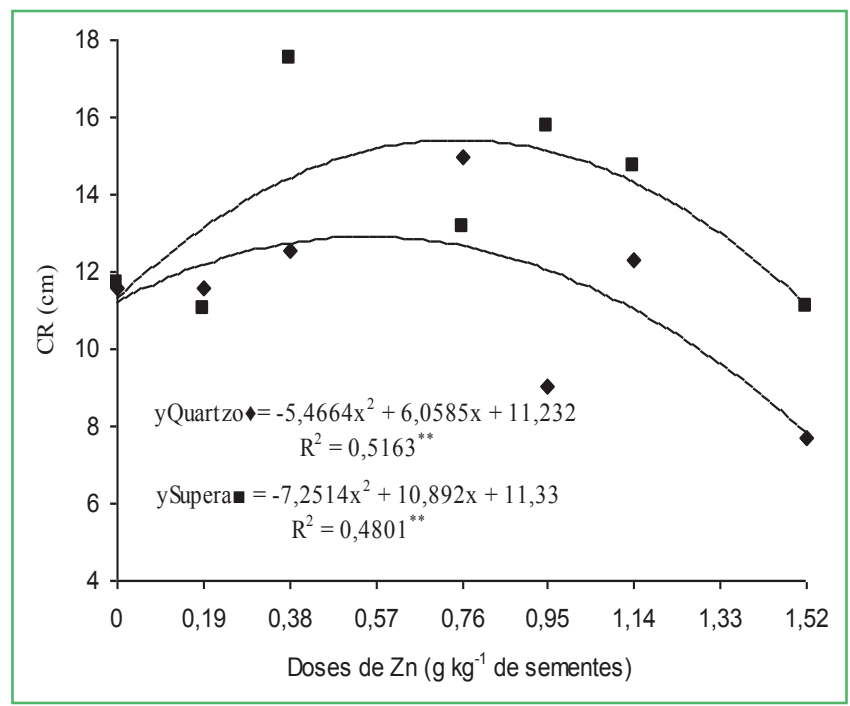

FIGURA 3: Comprimento da plântula inteira de trigo (CPI), cultivares Quartzo e Supera, em função de doses de $\mathrm{Zn}$ aplicadas via tratamento de sementes. UEPG, Ponta Grossa, PR, 2011.

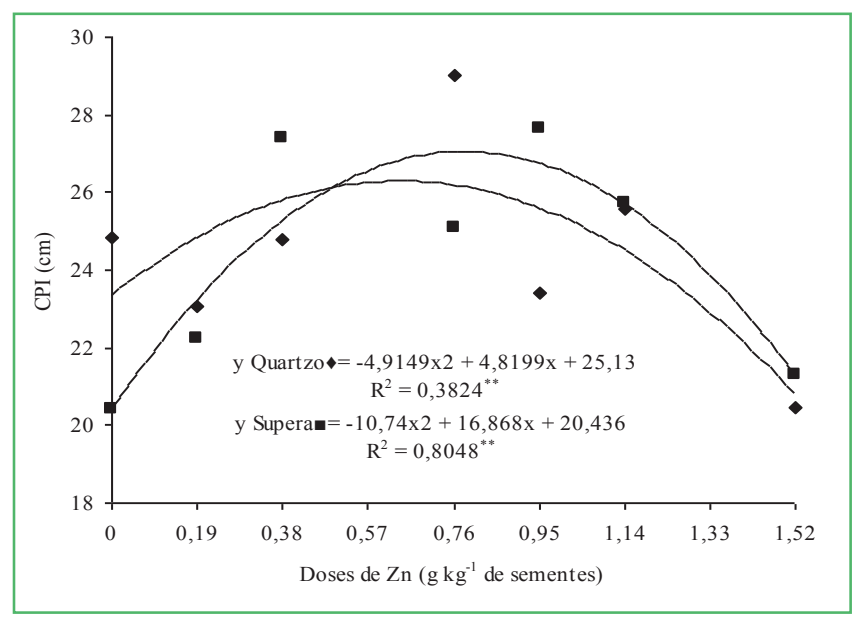

A análise estatística revelou significância para a interação entre cultivares de trigo e doses de $\mathrm{Zn}$ aplicadas via tratamento de sementes para as variáveis fitomassa fresca da parte aérea (FMFPA), fitomassa fresca da raiz (FMFR) e fitomassa fresca da plântula inteira (FMFPI) $(\mathrm{p}<0,01)$.

A cultivar Quartzo não se ajustou a nenhuma equação quando da análise de regressão para a variável FMFPA, apresentando média de 80,5mg.plântula ${ }^{-1} \mathrm{e}$ $\mathrm{CV}$ de $5,75 \%$. A cultivar Supera respondeu de forma quadrática às doses de $\mathrm{Zn}$ aplicadas via semente, havendo acréscimo de 31,63\% no valor de FMFPA, quando do ponto de máxima eficiência, o qual foi obtido com a dose de $0,86 \mathrm{~g}$ de $\mathrm{Zn}_{\mathrm{kg}}{ }^{-1}$ de sementes $(78,32 \mathrm{mg}$. plântula $\left.{ }^{-1}\right)$, a partir dessa dose houve decréscimo nos valores de FMFPA (Figura 4). Contudo, a cultivar Quartzo apresentou em média, 8,5mg.plântula ${ }^{-1}$ a mais que o valor médio de FMFPA obtido para a cultivar Supera.

Quando da análise de regressão para a variável FMFR, a cultivar Quartzo se ajustou a uma equação de primeiro grau decrescente, apresentando desta forma, descréscimo nos valores de FMFR à medida que se elevou as doses de Zn aplicadas via semente (Figura 5). As doses de $\mathrm{Zn}$ não influenciaram significativamente a FMFR da cultivar Supera, apresentando média 71,46mg. plântula ${ }^{-1}$ e CV de $12,06 \%$, todavia, essa média foi 
maior que a da cultivar Quartzo em 11,8mg.plântula ${ }^{-1}$. Em contrapartida, Pereira et al. (2010) ao estudarem a aplicação de $\mathrm{Zn}$ via tratamento de sementes em sorgo, obtiveram resposta significativa para FMFR, inferindo que o $\mathrm{Zn}$ ajudou no desenvolvimento inicial do sistema radicular das plântulas.

FIGURA 4: Fitomassa fresca da parte aérea de plântulas de trigo (FMFPA), cultivares Quartzo e Supera, em função de doses de $\mathrm{Zn}$ aplicadas via tratamento de sementes. UEPG, Ponta Grossa, PR, 2011.

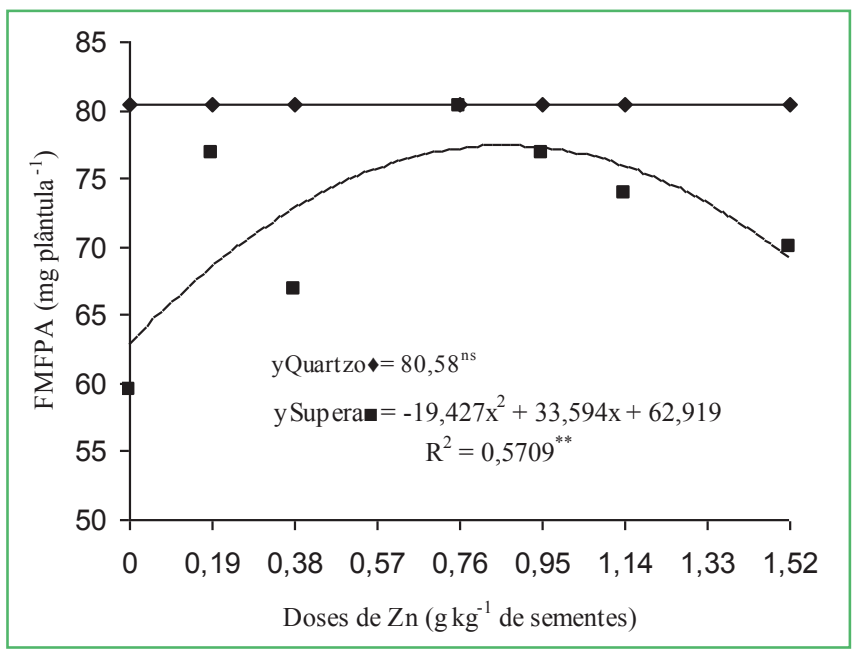

$\mathrm{O}$ efeito benéfico do tratamento de sementes de trigo com $\mathrm{Zn}$, sobre o comprimento de plântulas, pode estar associado ao fato do elemento ativar as enzimas desidrogenases, aldolases, enolases e isomerases, intensificando a respiração e, consequentemente, a produção de ATP para os processos que demandam energia, bem como o fornecimento de precursores para várias rotas biossintéticas. $\mathrm{O} \mathrm{Zn}$ também ativa as peptidases, intensificando a hidrólise das proteínas de reserva e, com isso, a suplementação de esqueletos carbônicos ao eixo embrionário, acelerando ou intensificando seu crescimento. Ativa também as enzimas RNA e DNA polimerases e, consequentemente a síntese de proteínas pelo eixo embrionário, o qual originará a plântula. Além disso, o Zn é necessário para a síntese de auxina, fitormônio que participa do processo de divisão e alongamento celular (MARENCO; LOPES, 2007; TAIZ; ZEIGER, 2009). Estes processos sendo intensificados nas sementes em germinação, provavelmente o eixo embrionário originará uma plântula mais vigorosa.
FIGURA 5: Fitomassa fresca da raiz de plântulas de trigo (FMFR), cultivares Quartzo e Supera, em função de doses de $\mathrm{Zn}$ aplicadas via tratamento de sementes. UEPG, Ponta Grossa, PR, 2011.

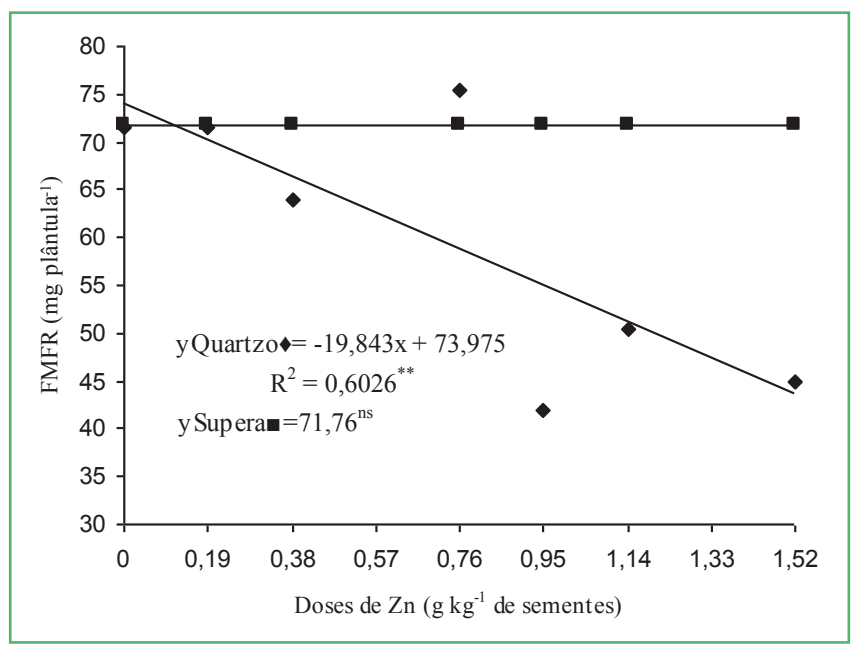

Para a variável FMFPI, a cultivar Quartzo apresentou resposta linear decrescente às doses de $\mathrm{Zn}$ aplicadas via semente, apresentando média de $140,7 \mathrm{mg}$. plântula ${ }^{-1}$. A cultivar Supera apresentou valor médio de $143 \mathrm{mg}_{\text {.plântula }}{ }^{-1}$ e CV de 9,05\%, não se ajustando a nenhuma equação quando da análise de regressão polinomial (Figura 6). Da mesma forma, Bonnecarrère et al. (2003) ao estudar doses de Zn via semente em arroz, concluíram que o Zn não influenciou significativamente a FMFPI.

A fitomassa seca da parte aérea (FMSPA) e da plântula inteira (FMSPI) apresentaram significância para a interação entre os fatores cultivares de trigo e doses de $\mathrm{Zn}$ aplicadas via tratamento de sementes quando submetidas à análise de variância $(p<0,01)$. Para a variável fitomassa seca da raiz (FMSR), houve significância para cultivares de trigo $(p<0,01)$ e para doses de $\mathrm{Zn}$ aplicadas via tratamento de sementes $(p<0,05)$, não existindo para a interação entre os dois fatores.

A cultivar Quartzo não se ajustou a nehuma equação quando da análise de regressão para a variável FMSPA, apresentando média de 6,7mg.plântula ${ }^{-1}$ e CV de 6,23\%. A cultivar Supera respondeu de forma quadrática as doses de $\mathrm{Zn}$ aplicadas via semente para FMSPA, havendo acréscimo até a dose de $0,98 \mathrm{~g}$ de $\mathrm{Zn} \cdot \mathrm{kg}^{-1}$ de sementes, a partir desse ponto houve decréscimo nos valores (Figura 
7). Quando da dose de máxima eficiência a FMSPA foi de 8,15mg.plântula ${ }^{-1}$, correspondendo a 40,3\% de acréscimo em relação ao tratamento sem $\mathrm{Zn}$ para a cultivar Supera (média de 7,0mg.plântula ${ }^{-1}$ ).

FIGURA 6: Fitomassa fresca da plântula inteira de plântulas de trigo (FMFPI), cultivares Quartzo e supera, em função de doses de $\mathrm{Zn}$ aplicadas via tratamento de sementes. UEPG, Ponta Grossa, PR, 2011.

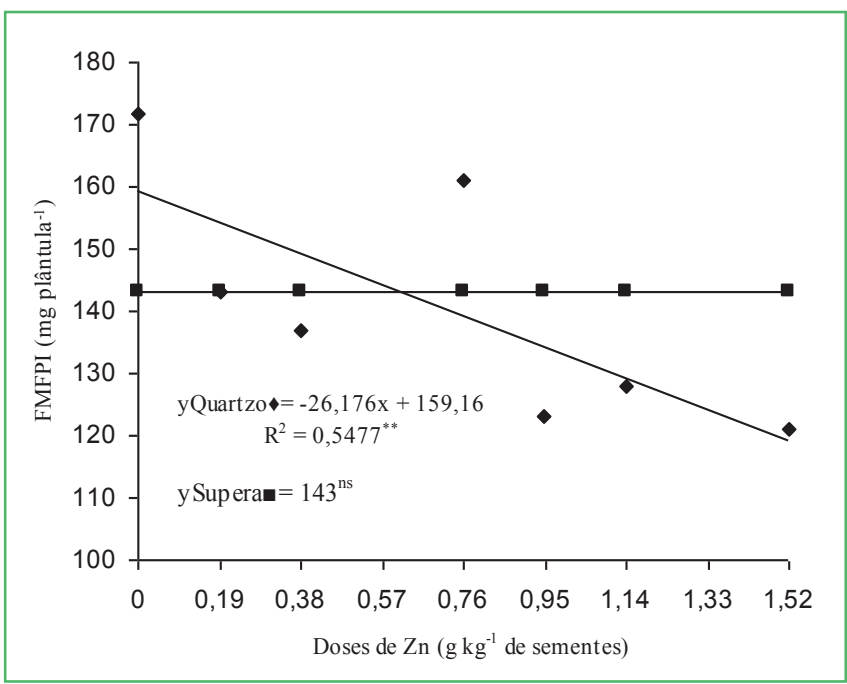

Na cultura do arroz, Fageria (2002) e Bonnecarrère et al. (2003) constataram influência significativa de doses de $\mathrm{Zn}$, acarretando aumento dos valores de FMSPA. Rozane et al. (2008) obtiveram resultados similares para a cultivar Supera, com a dose $0,86 \mathrm{~g}$ de ${\mathrm{Zn} . \mathrm{kg}^{-1} \mathrm{de}}^{\mathrm{d}}$ sementes na forma de sulfato, aumentando em $48 \%$ a FMSPA de plântulas de arroz. Entretanto, Pereira et al. (2007) ao estudarem quatro doses de Zn, verificaram que a adição de Zn não influenciou a FMSPA de plântulas de milho. De maneira semelhante, Prado et al. (2007) na cultura do trigo e Funguetto et al. (2010) na cultura do arroz, observaram que não houve influência de doses de Zn aplicadas via tratamento de semente para a variável em questão.

A cultivar Supera apresentou valor de FMSR superior em 19\% à Quartzo independentemente da dose de $\mathrm{Zn}$ aplicada via tratamento de sementes (Tabela 2). Quando da análise de regressão polinomial para doses independentemente da cultivar, a média obtida para FMSR foi de 6,68mg.plântula ${ }^{-1}$ e o CV de 9,1\%. Rozane et al. (2008) na cultura do arroz e Leal et al. (2007) na cultura do milho, também verificaram que não houve efeito significativo para a variável FMSR quando aplicadas doses de $\mathrm{Zn}$ via sementes. Porém, Prado et al. (2008) observaram acúmulo significativo de FMSR em plântulas de arroz quando do tratamento de sementes com $\mathrm{ZnSO}_{4} \cdot 7 \mathrm{H}_{2} \mathrm{O}$.

FIGURA 7: Fitomassa seca da parte aérea de plântulas de trigo (FMSPA), cultivares Quartzo e Supera, em função de doses de $\mathrm{Zn}$ aplicadas via tratamento de sementes. UEPG, Ponta Grossa, PR, 2011.

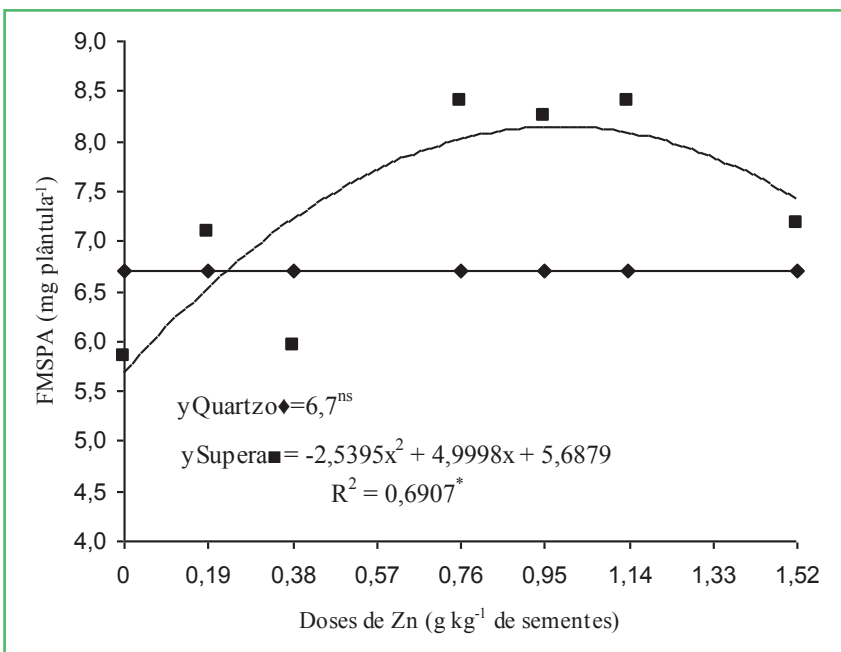

TABELA 2: Fitomassa seca da raiz de plântulas de duas cultivares de trigo submetidas a sete doses de $\mathrm{Zn}$ via tratamento de sementes. UEPG, Ponta Grossa, PR, 2011.

\begin{tabular}{lc}
\hline Cultivares de trigo & $\begin{array}{c}\text { Fitomassa seca de raiz } \\
\left.(\mathrm{mg} \text { plântula })^{-1}\right)\end{array}$ \\
\hline Quartzo & $6,0 \mathrm{~b}^{*}$ \\
Supera & $7,4 \mathrm{a}$ \\
Média & 6,7 \\
CV $(\%)$ & 13,18 \\
\hline
\end{tabular}

"Médias seguidas da mesma letra na coluna não diferem entre si pelo teste de Tukey a $5 \%$.

Para a cultivar Quartzo não houve ajuste quando da regressão polinomial para a variável FMFPI, apresentando média de $12,8 \mathrm{mg}$.plântula ${ }^{-1}$ e CV de $6,9 \%$. A FMSPI da cultivar Supera aumentou em $14,73 \%$ quando da dose $0,92 \mathrm{~g} . \mathrm{Zn} \cdot \mathrm{kg}^{-1}$ de sementes, apresentando neste ponto $15,6 \mathrm{mg}$.plântula ${ }^{-1}$ e média de 14,6mg.plântula ${ }^{-1}$ (Figura 8). Prado e Mouro (2007) observaram que o $\mathrm{ZnSO}_{4} .7 \mathrm{H}_{2} \mathrm{O}$ provocou diminuição 
da FMSPI em sorgo, resultados não condizentes com os obtidos por Ribeiro e Santos (1996) em milho e arroz e Rozane et al. (2008) em arroz, uma vez que obtiveram ganhos significativos de FMSPI quando do tratamento de sementes com $\mathrm{ZnSO}_{4} .7 \mathrm{H}_{2} \mathrm{O}$.

FIGURA 8: Fitomassa seca da plântula inteira para as cultivares de trigo (FMSPI), cultivares Quartzo e Supera, em função das doses de $\mathrm{Zn}$ aplicadas via tratamento de sementes. UEPG, Ponta Grossa, PR, 2011.

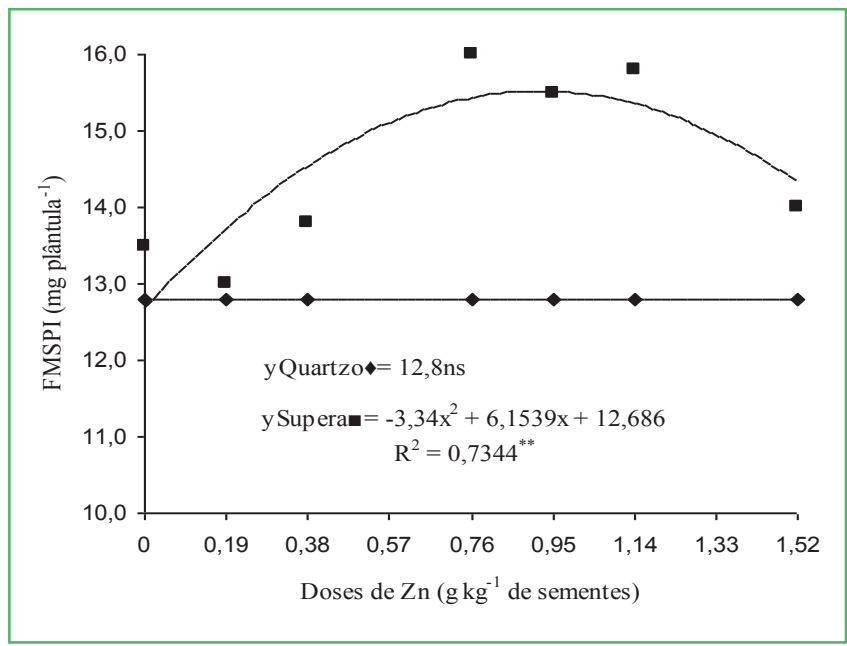

Observou-se que a cultivar Supera foi mais responsiva à aplicação de $\mathrm{Zn}$ quanto às variáveis avaliadas para o teste de vigor de sementes. $\mathrm{O}$ resultado pode ser atribuído a variações genéticas entre as cultivares estudadas quanto a adição de $\mathrm{Zn}$ visando promover o crescimento. O Zn está envolvido em rotas metabólicas responsáveis pelo crescimento das plântulas, como estímulo à sintese de auxina que promove divisão, alongamento e diferenciação celular; ativação de enzimas responsáveis pela respiração, acelerando a produção de compostos estruturais e metabólicos (respiração de crescimento), além do estímulo a síntese de proteínas, um dos principais componentes de membranas (proteínas periféricas e integrais) e enzimas responsáveis por processos de síntese e incorporação, podendo, com isso, aumentar o crescimento e a fitomassa de plântulas.

A germinação de sementes de trigo não foi influenciada pelas doses de $\mathrm{Zn}$ aplicadas via tratamento de sementes, entretanto, a germinação da cultivar Quartzo foi superior à Supera.
Quanto ao vigor, as cultivares responderam de forma diferenciada às doses de $\mathrm{Zn}$ aplicadas via tratamento de sementes. A cultivar Quartzo teve o comprimento de raiz e de plântula inteira aumentado até as doses de 0,50 e 0,56g.Zn. $\mathrm{kg}^{-1}$ de sementes, respectivamente. Doses de $\mathrm{Zn}$ entre 0,76 e 1,04g. $\mathrm{kg}^{-1} \mathrm{de}$ sementes proporcionaram maior vigor às sementes de trigo cultivar Supera. Sabendo-se da deficiência de $\mathrm{Zn}$ no solo e de posse destas informações pode-se inferir que a germinação destas cultivares não será reduzida, podendo o tratamento de sementes ser uma boa opção para prevenir sintomas de deficiência já no início do ciclo da cultura. Para a cultivar Supera, pode-se esperar até a dose máxima de $1,04 \mathrm{~g}$ de $\mathrm{Zn} \cdot \mathrm{kg}^{-1}$ de semente aumento no vigor, ou seja, melhor desenvolvimento inicial.

A partir dos resultados é possível concluir que as doses de zinco aplicadas via tratamento de sementes não influenciaram a germinação de sementes das cultivares de trigo Quartzo e Supera, porém a germinação da cultivar Quartzo foi superior.

$\mathrm{O}$ vigor das sementes das cultivares de trigo Quartzo e Supera foi influenciado pelas doses de $\mathrm{Zn}$ testadas via tratamento de sementes, sendo a cultivar Supera mais responsiva, uma vez que, apresentou aumentos significativos em maior número de variáveis do vigor.

\section{Referências}

BONNECARRÈRE, R. A. G.; LONDERO, F. A. A.; SANTOS, O. S.; SCHMIDT, D.; PILAU, F. G.; MANFRON, P. A.; DOURADO NETO, D. D. Resposta de genótipos de arroz irrigado à aplicação de zinco. Revista da Faculdade de Zootecnia, Veterinária e Agronomia, Uruguaiana, v. 10, n. 1, p. 109-116, 2003.

BRASIL. Ministério da Agricultura, Pecuária e Abastecimento. Regras para análise de sementes. Ministério da Agricultura, Pecuária e Abastecimento. Secretaria de Defesa Agropecuária. Brasília: Mapa/ACS, 2009. 395 p.

BRASIL. Ministério da Agricultura, do Abastecimento e da Reforma Agrária. Normas para produção de sementes fiscalizadas. Porto Alegre: CESM/RS, 1993. 140 p.

BRUNETTA, D.; DOTTO, S.; BASSOI, M.; SCHEEREN, P. L. Cultivar certa. Revista Grupo Cultivar, Pelotas, n. 6, v. 60, p. 3234, 2004.

COLLE, C. A. A cadeia produtiva do trigo no Brasil: contribuição para a geração de emprego e renda. 1998. $80 \mathrm{f}$. Dissertação (Mestrado em Economia) - Universidade Federal do Rio Grande do Sul, Porto Alegre. 1998. 
CONAB. Quarto levantamento, janeiro de 2011. Acompanhamento da Safra Brasileira de Grãos 2010/2011. 2011. Brasília. Disponível em: <http://www.conab.gov.br/OlalaCMS/uploads/ arquivos/11_01_06_08_41_56_boletim_graos_40_lev_ safra_2010_2011.pdf $>$. Acesso em: 11 jan. 2011.

EMBRAPA TRIGO. Centro Nacional de Pesquisa de Trigo, Passo Fundo. O trigo no Brasil. 2007. Disponível em $<$ http://www.cnpt. embrapa.br/aunidade/trigo_brasil.htm>. Acesso em: 19 dez. 2010.

FAGERIA, N. K. Influence of micronutrients on dry matter yield and interaction with other nutrients in annual crops. Pesquisa Agropecuária Brasileira, Brasília, v. 37, n. 12, p. 1765-1772, 2002.

FAVARIN, J. L.; MARINI, J. P. Importância dos micronutrientes para a produção dos grãos. Sociedade Nacional da Agricultura, Piracicaba. 2000. Disponível em: <http://alternex.com.br /\%7Esnafagram/artigos/artitec-micronutrientes.htm $>$. Acesso em: 05 fev. 2011.

FUNGUeTTO, C. I.; PINTO, J. F.; BAUDET, L.; PESKE, S. T. Desempenho de sementes de arroz irrigado recobertas com zinco. Revista Brasileira de Sementes, Pelotas, v. 32, n. 2, p. 117-123, 2010.

KRZYZANOWSKI, F. C.; FRANÇA NETO, J. B.; HENNING, A. A. Relato dos testes de vigor disponíveis para as grandes culturas. Informativo ABRATES, Londrina, v. 1, n. 2, p. 11-14, 1991.

LEAL, R. M.; FRANCO, C. F.; BRAGHIROLLI, L. F.; ARTUR, A. G.; SABONARO, D. Z.; BETTINI, M.; PRADO, R. M. Efeito da aplicação de zinco em sementes sobre a nutrição e a produção de fitomassa seca de plantas de milho. Acta Scientiarum Agronomy, Maringá, v. 29, n. 4, p. 491-496, 2007.

LEANDRO, W. M.; OLIVEIRA, J. P.; CARVALHO, M. C.; MEDEIROS, J. C.; FREITAS, L. F.; SOUTO, M. L.; FERREIRA, R. G. Efeito da gessagem e da adubação com micronutrientes na produção do algodoeiro no cerrado de Goiás. Empresa Brasileira de Pesquisa Agropecuária. 2002 Disponível em: <http://www.cnpa. embrapa.br/produtos/algodao/publicacoes/trabalhos_cba4/366. pdf>. Acesso em: 14 dez. 2010.

MALAVOLTA, E. Manual de nutrição mineral de plantas. 1 ed. São Paulo: Agronômica Ceres, 2006. 638 p.

MALTA, M. R. Absorção, translocação, compartimentalização e metabolismo do zinco aplicado via foliar em mudas de cafeeiro (Coffea arabica L.). 2000. 29 f. Dissertação (Mestrado em Agronomia) -Universidade Federal de Lavras, Lavras. 2000.

MARENCO, R. A.; LOPES, N. F. Fisiologia Vegetal. 2 ed. Viçosa: Editora UFV, 2007. 469 p.

OHSE, S.; MARODIM, V.; SANTOS, O. S.; LOPES, S. J.; MANFRON, P. A. Germinação e vigor de sementes de arroz irrigado tratadas com Zinco, Boro e Cobre. Revista da Faculdade de Zootecnia, Veterinária e Agronomia, Uruguaiana, v. 7/8, n. 1, p. 41-50, 2001.

OHSE, S.; SANTOS, O. S.; MARODIM, V.; MANFRON, P.A. Efeito do tratamento de sementes de arroz irrigado com zinco em relação à aplicação no substrato. Revista da Faculdade de Zootecnia, Veterinária e Agronomia, Uruguaiana, v. 5/6, n. 1, p. 32-42, 1999.
PARDUCCI, S.; SANTOS, O. S.; CAMARGO, R. P.; LEÃO, R. M. A.; BATISTA, R. B. Micronutrientes biocrop. Campinas: Microquímica, 1989. $101 \mathrm{p}$.

PEREIRA, N. M. Z.; ERNANI, P. R.; SANGOI, L. Disponibilidade de zinco para o milho afetada pela adição de $\mathrm{Zn}$ e pelo $\mathrm{pH}$ do solo. Revista Brasileira de Milho e Sorgo, Lages, v. 6, n. 3, p. 273-284, 2007.

PEREIRA, M. M.; NETO, A. J. M.; COSTA, E. R.; SANTOS, F. P.; LIMA, P. B. S. O. Influência do tratamento de sementes com micronutrientes (Zn e Mo) sobre o desenvolvimento de plântulas de sorgo (Sorghum bicolor L.). XXVIII Congresso Nacional de Milho e Sorgo. Goiânia. 2010. Disponível em: <http:// efazweb.com.br/clientes/resumos/ 0426.pdf $>$. Acesso em: 12 mar. 2011.

PESSOA, A. C. S.; SANTOS, O. S.; BORTOLUZZI, A. L.; VEDUIN, J. V. R.; PILLON, C. N. Épocas e formas de aplicação de zinco em milho cultivado em solução nutritiva. Ciência Agrícola, Maceió, v. 4, p. 43-52, 1996.

PRADO, R. M.; FRADE, E. F.; MOUTA, E. R.; JOÃO, A. C. G.; COSTA, R. S. S. Crescimento inicial e estado nutricional do trigo submetido à aplicação de zinco via semente. Revista de la ciencia del suelo y nutrición vegetal, Temuco, v. 7, n. 2, p. 22-31, 2007.

PRADO, R. M.; MOURO, M. C. Fontes de zinco aplicado em sementes de sorgo cv. BRS 310 e o crescimento inicial. Semina: Ciências Agrárias, Londrina, v. 28, n. 3, p. 355-364, 2007.

PRADO, R. M.; ROZANE, D. E.; SIMÕES, R. R.; ROMUALDO, L. M. Resposta de plântulas de arroz à aplicação de zinco via semente. Magistra, Cruz das Almas, v. 20, n. 1, p. 87-94, 2008.

RAIJ, B. Fertilidade do solo e adubação. Piracicaba: Ceres/ Potafos, 1991. $343 \mathrm{p}$.

RIBEIRO, N. D.; SANTOS, O. S. Aproveitamento do zinco aplicado na semente na nutrição da planta. Ciência Rural, Santa Maria, v. 26, n. 1, p. 159-165, 1996.

ROZANE, D. E.; PRADO, R. M.; ROMUALDO, L. M.; SIMÕES, R. R. Resposta de plântulas de arroz cv. BRS - Soberana à aplicação de zinco via semente. Ciência e Agrotecnologia, Lavras, v. 32, n. 3, p. 847-854, 2008

SLATON, N. S.; WILSON JUNIOR, C. E.; NTAMATUNGIRO, S.; NORMAN, R. J.; BOOTHE, D. L. Evaluation of zinc seed treatments for rice. Agronomy Journal, Madison, v. 93, n. 1, p. 3-98, 2001.

TAIZ, L.; ZEIGER, E. Fisiologia vegetal. 4. ed. Porto Alegre: Artmed, 2009. 820 p.

WEBB, M. J.; LONERAGAN, J. F. Effect of zinc deficiency on growth, phosphorus concentration, and phosphorus toxicity of wheat plants. Soil Science Society of America Journal, Madison, v. 52, n. 6, p. 1676-1680, 1988. 